\title{
Dose Optimisation: A Strategy to Improve Tolerability and Lower Antiretroviral Drug Prices in Low and Middle Income Countries
}

\author{
Andrew Hill ${ }^{*}, 1$, Jinatanat Ananworanich ${ }^{2}$ and Alexandra Calmy ${ }^{3}$ \\ ${ }^{1}$ Pharmacology Research Laboratories, Liverpool University, Liverpool, UK \\ ${ }^{2}$ The Thai Red Cross AIDS Research Centre and Chulalongkorn University, Bangkok, Thailand \\ ${ }^{3}$ Medecins Sans Frontieres Access Campaign, Geneva, Switzerland, Geneva University Hospital, HIV Unit, Switzerland
}

\begin{abstract}
Four million people have been initiated on antiretroviral treatment in low and middle income countries. However, an additional 5 million people eligible for treatment are not receiving it. Of the 27-29 million people infected with HIV but not currently receiving treatment, most will need to start antiretrovirals as their disease progresses. Funding for access programmes is restricted, partly because of the Global Financial Crisis. Antiretroviral treatment programmes have to lower overall costs, so that the maximum number of people with HIV can be treated for limited budgets. Antiretroviral treatment can account for the majority of the total cost of access programmes.

During the development of antiretrovirals, several doses are normally evaluated in Phase 2 dose-ranging trials. In the case of efavirenz, lopinavir/ritonavir and raltegravir, there was no difference in efficacy between doses evaluated at Phase 2, but the higher doses were then taken into Phase 3 registration trials, leading to regulatory approval.

Re-analysis of the dose-ranging trials of raltegravir showed equal efficacy for doses in the range of 100 to $600 \mathrm{mg}$ twice daily. The main Phase 2 trial of efavirenz, DMP-005, suggests that a 400mg once daily dose should show equal efficacy to the standard $600 \mathrm{mg}$ once daily dose. The dose-ranging trials of lopinavir/ritonavir showed the highest efficacy at the 200/100mg mg twice daily dose, compared with the standard 400/100 mg twice daily dose.

Re-optimisation of doses could dramatically lower costs of first and second-line treatment for low and middle income countries. For example, it may be possible to manufacture raltegravir $100 \mathrm{mg}$ twice daily for US $\$ 75-100$, allowing firstline use in low income countries. Costs of efavirenz could be lowered by $30 \%$, and lopinavir/ritonavir by $35 \%$, using reoptimised doses. There may also be safety benefits to these new doses.
\end{abstract}

Keywords: Nucleoside analogues, protease inhibitors, non nucleosides, health economics, developing countries, pharmacology, HIV RNA, HIV clinical trials.

\section{INTRODUCTION}

Of the 33 million people currently infected with HIV/AIDS, over $90 \%$ live in low income countries [1]. Although 4 million people have been started on antiretroviral treatment in these countries, an additional five million people in low and middle income countres are eligible for treatment but are not receiving it [1]. Most of the 29 million people infected with HIV, but currently untreated, will require antiretrovirals at some time in the future, if they are identified and tested. In addition, there are an estimated three million new HIV infections every year [1].

Given these combined pressures, there is still a dire need for further upscale in HIV treatment programmes. We should therefore be planning for large upscale in HIV treatment programmes, in order to treat between 10-15 million people with antiretrovirals in low or middle income countries within the next 5 years. However, there are concerns over whether

*Address correspondence to this author at the Pharmacology Research Laboratories, Liverpool University, 70 Pembroke Place, Liverpool, L69 3GF, UK; Tel: +44 7834364 608; Fax: +44 208675 1716;

E-mail: microhaart@aol.com funding for access programmes will be large enough to allow this number of patients to be treated [2-4].

Drug costs are already accounting for as much as $60 \%$ of antiretroviral treatment program costs in several countries, and any effort to decrease drug cost is likely to have a major benefit. API (active product ingredient) production costs are the biggest driver of antiretroviral drug prices among generic manufacturers [3]: a given percentage reduction in dosage will translate into a virtually equivalent percentage reduction in drug pricing. Clearly, when millions of patients are being treated, small reductions in the annual per-patient cost of treatment could lead to significant reductions in the global cost of HIV treatment [5].

In this review paper, we discuss the use of dose optimisation to lower antiretroviral drug costs and improve tolerability and convenience.

\section{HIV DRUG COSTS IN LOW INCOME COUNTRIES}

Table 1 shows the minimum cost of antiretrovirals in low income countries (based on prices from the Clinton Foundation for Least Developed Countries [5], from Thailand (representing a middle income country) and the 
USA as a reference developed country. The cost of antiretrovirals in low income countries is typically $90-99 \%$ lower than in North America. The cost of manufacture in low income countries is closely related to the cost of the Active Product Ingredient (API) - this is the actual antiretroviral substance. This is particularly true for generic drugs [6]. Economies of scale and improved manufacturing techniques have lowered the minimum costs of antiretrovirals over the past ten years, and annual costs of $\$ 80$ per person-year of treatment are now possible for combinations such as $\mathrm{d} 4 \mathrm{~T} / 3 \mathrm{TC} / \mathrm{NVP}[2,5]$. However the cost of protease inhibitors or raltegravir is substantially higher (Table 1).

Table 1. Annual Per-Patient Prices of Antiretrovirals by National Income: Low (Africa), Middle (Thailand) and High (USA)

\begin{tabular}{|c|c|c|c|c|}
\hline \multirow{2}{*}{ Drug } & \multirow{2}{*}{ Dose } & \multicolumn{2}{|c|}{ Annual Price Per Patient (US \$) } \\
\cline { 3 - 5 } & & Africa & Thailand & USA \\
\hline \hline lamivudine (3TC) & $300 \mathrm{mg}$ OD & 34 & 177 & 3923 \\
\hline stavudine (d4T) & $30 \mathrm{mg}$ BID & 25 & 84 & 4447 \\
\hline zidovudine (ZDV) & $300 \mathrm{mg}$ BID & 96 & 345 & 4584 \\
\hline didanosine (ddI) & $400 \mathrm{mg}$ OD & 240 & 1305 & 3988 \\
\hline tenofovir (TDF) & $300 \mathrm{mg}$ OD & 99 & 470 & 6719 \\
\hline nevirapine (NVP) & $200 \mathrm{mg}$ BID & 40 & 251 & 4912 \\
\hline efavirenz (EFV) & $600 \mathrm{mg}$ OD & 105 & 282 & 5869 \\
\hline lopinavir/r (LPV/r) & $400 / 100 \mathrm{mg}$ BID & 470 & 2004 & 8586 \\
\hline atazanavir/r (ATV/r) & $300 / 100 \mathrm{mg}$ OD & $\mathrm{n} / \mathrm{a}$ & 3383 & 10635 \\
\hline raltegravir (RAL) & $400 \mathrm{mg}$ BID & 1113 & $3480 *$ & 9855 \\
\hline
\end{tabular}

Data Sources:

Low income countries - Clinton HIV/AIDS website summary 2009 [5].

Thailand (middle income country). The Thai Red Cross AIDS Research Center (Exchange rate used was $33.45 \mathrm{Baht} / 1 \mathrm{USD}$ ).

USA (Wholesale Acquisition Costs) - MedSpan Price Check PC.

*Unofficial price. Medication is not yet available in Thailand.

\section{OPTIMISATION OF DOSES FOR ANTIRETROVIRALS}

Many clinicians think of drug dosing as fixed and unchanging, but the doses of three antiretrovirals have been lowered since they were first launched. The dose of zidovudine was reduced from $1800 \mathrm{mg}$ daily to $600 \mathrm{mg}$ daily, after dose-ranging trials showed equivalent efficacy but improved safety at the lower dose [7]. The dose of didanosine was also reduced, for similar reasons [8].

The dose of the nucleoside analogue stavudine was reduced from $40 \mathrm{mg}$ to $30 \mathrm{mg}$ twice daily after a metaanalysis of dose-ranging studies showed the same efficacy at the lower dose, but with an improved safety profile. Patients who took the $30 \mathrm{mg}$ twice daily dose of stavudine had a lower risk of peripheral neuropathy and were less likely to discontinue treatment [9]. The World Health Organisation now recommends the $30 \mathrm{mg}$ twice daily dose of stavudine for all patients [10].

During the dose-selection phase of HIV drug development, clinical trials of 30-100 patients per arm are used to evaluate the efficacy and safety of several doses. In some cases, there is a dose-limiting toxicity at a higher dose, or a lack of efficacy at a lower dose, which makes the dose selection straightforward. However in most cases, these trials can show similar levels of efficacy between a range of doses. In these situations, pharmaceutical companies tend to progress with higher doses, to maximise the potential for long-term efficacy and possibly to ensure efficacy even when drug interactions lower the concentration of the new antiretroviral. However, choosing higher doses can compromise patient safety, and the higher doses are more expensive to manufacture. For example, if stavudine had been approved at the $30 \mathrm{mg}$ twice daily dose, thousands of cases of severe peripheral neuropathy could have been avoided, but the efficacy of stavudine would not have been affected. The dose selection for the non-nucleoside rilpivirine is a good example of this process. In the TMC278 C204 trial, doses of $25-150 \mathrm{mg}$ once daily showed similar efficacy as first-line treatment with two nucleoside analogues [11]. At first a $75 \mathrm{mg}$ dose was chosen for phase II trials from the TMC278-C204 trial; concerns about safety led to a dose reduction of $25 \mathrm{mg}$ for phase II trials, without apparent concerns about virological efficacy.

\section{DOSE SELECTION FOR RALTEGRAVIR}

The STARTMRK trial has established the efficacy of the $400 \mathrm{mg}$ twice daily dose versus efavirenz in treatment naïve patients [12], while the BENCHMRK trials have shown efficacy for raltegravir in treatment experienced patients [13]. These pivotal trials all used the 400mg twice daily dose, which has been approved by regulatory authorities in North America and Europe.

Currently, raltegravir is not available for use in low income countries - but the cost could be set as much as for $\$ 1113$ per person-year for the $400 \mathrm{mg}$ twice daily dose [2], and this high price could severely limit use in Africa or Asia. The Clinton Foundation has estimated a future price of $\$ 300$ 600 per person-year for raltegravir at this dose, if production can be up-scaled [14].

Raltegravir has been evaluated in treatment naïve patients at doses ranging from $100 \mathrm{mg}$ to $600 \mathrm{mg}$ twice daily. The efficacy and safety of this integrase inhibitor was very similar across the range of doses evaluated (Table 2). The efficacy of raltegravir was first evaluated in a 10 day monotherapy study, in 35 treatment naïve, HIV-infected individuals [15]. The doses evaluated were 100, 200, 400 and $600 \mathrm{mg}$ twice daily. After 10 days of dosing, the $\log _{10}$ reductions in HIV RNA and the percentage of patients with HIV RNA $<400$ were the same at the four doses evaluated (Table 2a).

Subsequently, a 48 week trial in treatment naïve patients [16] showed no differences in efficacy between raltegravir doses of 100, 200, 400 and $600 \mathrm{mg}$ twice daily, given with tenofovir and lamivudine (Table $\mathbf{2 b}$ ). The rises in CD4 count were greatest for the $100 \mathrm{mg}$ twice daily dose $(+221$ cells $/ \mathrm{uL})$ and lowest for the $400 \mathrm{mg}$ twice daily dose $(+144$ cells $/ \mathrm{uL})$.

In addition, a 24 week trial was conducted in treatment experienced patients [17], evaluating raltegravir doses of 200, 400 and $600 \mathrm{mg}$ twice daily. This trial showed no difference in HIV RNA suppression rates between the doses (Table 2c). In this trial, the rises in CD4 count were greater 
at the $400 \mathrm{mg}$ twice daily dose $(+113$ cells/uL) relative to the $200 \mathrm{mg}$ twice daily dose $(+63$ cells/uL $)$.

Table 2a. Merck Phase 1b Trial of Raltegravir (RAL) - 10 Days of Monotherapy [15]

\begin{tabular}{|c|c|c|c|c|}
\hline RAL Dose (BID) & $\mathbf{1 0 0} \mathbf{m g}$ & $\mathbf{2 0 0} \mathbf{m g}$ & $\mathbf{4 0 0 m g}$ & $\mathbf{6 0 0} \mathbf{m g}$ \\
\hline \hline N & 7 & 7 & 6 & 8 \\
\hline Baseline CD4 & 415 & 343 & 256 & 569 \\
\hline Baseline HIV RNA & 4.65 & 4.53 & 4.58 & 4.97 \\
\hline Race (\% Caucasian) & $57 \%$ & $57 \%$ & $50 \%$ & $100 \%$ \\
\hline Gender (\% male) & $100 \%$ & $86 \%$ & $100 \%$ & $100 \%$ \\
\hline 10 Day Efficacy Data & & & \\
\hline Percent HIV RNA <400 & $57 \%$ & $57 \%$ & $50 \%$ & $50 \%$ \\
\hline Log reduction HIV RNA & -1.93 & -1.98 & -1.66 & -2.16 \\
\hline
\end{tabular}

Table 2b. Merck Phase 3 Trial of Raltegravir in Treatment Naïve Patients (48 Weeks) [16]

\begin{tabular}{|c|c|c|c|c|}
\hline RAL Dose (BID) & $100 \mathrm{mg}$ & $200 \mathrm{mg}$ & $400 \mathrm{mg}$ & $600 \mathrm{mg}$ \\
\hline $\mathrm{N}$ & 39 & 40 & 41 & 40 \\
\hline Baseline CD4 & 314 & 296 & 338 & 271 \\
\hline Baseline HIV RNA & 4.8 & 4.8 & 4.6 & 4.8 \\
\hline Race (\% non-Caucasian) & $82 \%$ & $65 \%$ & $66 \%$ & $65 \%$ \\
\hline Gender (\% male) & $85 \%$ & $73 \%$ & $90 \%$ & $73 \%$ \\
\hline \multicolumn{5}{|c|}{48 Week Efficacy Data (ITT) } \\
\hline Percent HIV RNA <400 & $97 \%$ & $85 \%$ & $98 \%$ & $90 \%$ \\
\hline Percent HIV RNA $<50$ & $85 \%$ & $83 \%$ & $88 \%$ & $88 \%$ \\
\hline 48 week CD4 rise (mean) & +221 & +146 & +144 & +187 \\
\hline
\end{tabular}

Table 2c. Merck 005 Trial of Raltegravir (RAL) in Experienced Patients [17]

\begin{tabular}{|c|c|c|c|}
\hline RAL Dose (BID) & $200 \mathrm{mg}$ & $400 \mathrm{mg}$ & $600 \mathrm{mg}$ \\
\hline $\mathrm{N}$ & 43 & 40 & 41 \\
\hline Baseline CD4 & 245 & 221 & 220 \\
\hline Baseline HIV RNA & 4.6 & 4.8 & 4.7 \\
\hline Race (\% non-Caucasian) & $84 \%$ & $78 \%$ & $71 \%$ \\
\hline Gender ( $\%$ male $)$ & $84 \%$ & $89 \%$ & $91 \%$ \\
\hline \multicolumn{4}{|c|}{24 Week Efficacy Data (ITT) } \\
\hline Percent HIV RNA <400 & $70 \%$ & $71 \%$ & $71 \%$ \\
\hline Percent HIV RNA $<50$ & $65 \%$ & $56 \%$ & $67 \%$ \\
\hline 48 week CD4 rise (mean) & +63 & +113 & +94 \\
\hline
\end{tabular}

Across the three dose-ranging trials, there is no consistent trend for improved HIV RNA reductions or greater rises in CD4 counts with increasing doses of raltegravir. The combined sample size for these dose-ranging trials, 312 patients - provides evidence for this lack of correlation between raltegravir dosing and efficacy.

If Clinton Foundation's predictions of cost for upscaled production of raltegravir are correct, the implication is that a $100 \mathrm{mg}$ twice daily dose could then be made for between $\$ 75-150$ per person-year, which is similar to the minimum price efavirenz or nevirapine (Table 1). If efficacy could be proved for a $100 \mathrm{mg}$ twice daily dose of raltegravir versus efavirenz in a large non-inferiority trial, this could then potentially allow first-line use of raltegravir in low income countries at an affordable price. If only the current $400 \mathrm{mg}$ formulation of raltegravir can be used, pharmacokinetic data is already available for raltegravir at the $400 \mathrm{mg}$ once daily dose, in combination with atazanavir [18]. There are clinical trials underway evaluating the $800 \mathrm{mg}$ once daily dose, and the pharmacokinetics of raltegravir, with a long terminal elimination half-life, may support once daily dosing [19]. However the dose-ranging trials in this review only evaluated twice-daily dosing.

\section{DOSE SELECTION FOR EFAVIRENZ}

The standard dose of efavirenz is $600 \mathrm{mg}$ once daily (manufactured in tablet strengths of 200 and $600 \mathrm{mg}$, both FDA approved). First-line treatment with two nucleoside analogues plus efavirenz is a widely accepted standard of care for developed and developing countries, based on multiple clinical trials showing efficacy advantages over other combinations [20]. The main side-effects of efavirenz involve the central nervous system (CNS). Efavirenz is also a known teratogen and is contraindicated in first trimester pregnancy. Phase 2 data suggests that efavirenz doses of 200 to $400 \mathrm{mg}$ once daily show similar antiviral efficacy to the approved dose of $600 \mathrm{mg}$ OD. There is the potential for lower doses to also improve the CNS adverse event profile.

The DMP-005 trial of efavirenz was conducted in 19961997, and was presented at the $5^{\text {th }}$ CROI meeting in Chicago, February 1998 [21], but was never published. 137 naïve patients were randomized to 24 weeks of treatment with zidovudine plus lamivudine with efavirenz at doses of $200 \mathrm{mg}, 400 \mathrm{mg}$ or $600 \mathrm{mg}$ once daily, or matching placebo. Summary baseline and 16 week efficacy data is shown in Table 3. There was no difference in HIV RNA suppression rates between the three doses of efavirenz. These efficacy results were sustained to week 24 . There were no systematic differences in adverse event profiles by treatment group, although there was a higher incidence of dizziness at the highest efavirenz dose, and more rash at the lowest dose. However, six patients withdrew from the efavirenz $600 \mathrm{mg}$ once daily arm owing to adverse events, versus none from the efavirenz $200 \mathrm{mg}$ group.

Genetic analysis of patients receiving efavirenz showed that plasma drug levels could be up to three times higher for those with a certain CYP2B6 allelic variant, seen most often in Africans [23]. In a separate analysis of 255 Dutch patients, females and those with low body weight had significantly higher efavirenz drug levels, and there was also an association between Asian or African race and higher efavirenz levels [24]. In analysis of the Swiss HIV cohort, patients taking efavirenz with higher drug levels were found to have a higher risk of nervous system side effects [25]. It is possible that efavirenz dose reductions may lower the incidence of these side-effects. 
Table 3. DMP-006 Trial of Efavirenz [21]

\begin{tabular}{|c|c|c|c|c|}
\hline Efavirenz Dose (OD) & 200mg & 400mg & $\mathbf{6 0 0 m g}$ & Placebo \\
\hline \hline N & 36 & 34 & 34 & 33 \\
\hline Baseline CD4 & 329 & 359 & 388 & 395 \\
\hline Baseline HIV RNA & 4.81 & 4.76 & 4.64 & 4.66 \\
\hline Baseline weight (kg) & 75 & 73 & 78 & 77 \\
\hline Race (\% Cauc/Afr) & $53 / 36 \%$ & $71 / 18 \%$ & $68 / 21 \%$ & $61 / 33 \%$ \\
\hline Gender (\% male) & $97 \%$ & $89 \%$ & $85 \%$ & $76 \%$ \\
\hline 16 Week Efficacy Data (ITT) & $86 \%$ & $85 \%$ & $79 \%$ & $39 \%$ \\
\hline Percent HIV RNA <400 & $83 \%$ & $68 \%$ & $67 \%$ & $15 \%$ \\
\hline Percent HIV RNA <50 & $8 \%$ & $59 \%$ & $8 \%$ \\
\hline Percent HIV RNA $<1$ & $50 \%$ & $39 \%$ & $59 \%$ \\
\hline 16 week CD4 rise (mean) & +136 & +106 & +110 & +96 \\
\hline \multicolumn{5}{|c|}{}
\end{tabular}

The initial dose-selection of efavirenz seems to have been influenced by a calculation of $\mathrm{Cmin} / \mathrm{IC} 50$ ratios, which suggested an advantage for the $600 \mathrm{mg}$ once daily dosage. However the clinical relevance of this in vitro prediction is unclear given the results seen in DMP-005. In addition, the mean body weight for patients in the DMP-005 trial was higher than would be expected for an Asian or African naïve patient population, where efavirenz drug levels are also expected to be higher.

The ENCORE 1 trial is comparing the efficacy and safety of first-line treatment with efavirenz at the standard $600 \mathrm{mg}$ once daily dose versus the $400 \mathrm{mg}$ once daily dose, in 600 patients, treated for 96 weeks [22]. If the $400 \mathrm{mg}$ dose of efavirenz proved to be effective in this trial, the cost of efavirenz could be lowered by $\$ 30$ per person per year in low income countries. Given that several million people are likely to use efavirenz in the low income countries, this dose reduction could translate to a cost saving of up to $\$ 100-200$ million over 5 years.

\section{DOSE SELECTION FOR LOPINAVIR/RITONAVIR}

The approved dose of lopinavir/ritonavir is $400 / 100 \mathrm{mg}$ twice daily. Originally, the two protease inhibitors were coformulated in a soft gelatin capsule with $133 \mathrm{mg}$ of lopinavir and $33 \mathrm{mg}$ of ritonavir (three capsules twice daily). The new heat-stable formulation $(200 / 50 \mathrm{mg}$ - two tablets twice daily) showed 18\% higher plasma AUC lopinavir levels and 24\% higher Cmax levels than the soft gelatin formulation [26], but also less variable plasma drug concentrations, no food dependence, and no need for refrigeration [26]. A similar study in treatment naïve people with HIV also showed higher lopinavir exposures for patients given the Meltrex formulation, compared to the soft-gel formulation [27]. Coformulated lopinavir/ritonavir tablets have also been used with additional ritonavir capsules, to further increase lopinavir exposure [28].

The Abbott 720 trial [29] evaluated three doses of lopinavir/ritonavir in treatment naïve patients. In sequential randomizations, two groups of treatment-naïve patients were given 48 weeks treatment with either:

\section{Group 1}

D4T/3TC + LPV/r 200/100 mg twice daily

D4T/3TC + LPV/r 400/100 mg twice daily

\section{Group 2}

$\mathrm{D} 4 \mathrm{~T} / 3 \mathrm{TC}+\mathrm{LPV} / \mathrm{r}$ 400/100 mg twice daily

D4T/3TC + LPV/r 400/200 mg twice daily

In Group 1, significantly more patients showed HIV RNA reductions below 50 copies in the 200/100 twice daily arm, compared to the $400 / 100 \mathrm{mg}$ twice daily arm $(\mathrm{p}<0.002)$, however this was driven more by adverse events than antiviral efficacy. In group 2, there was no difference in efficacy between the 200/100, 400/100 and 400/200mg twice daily doses of lopinavir/ritonavir. Summary results are shown in Table 4. There were no significant differences in CD4 rise between treatment groups. Plasma drug levels of lopinavir were higher for the 400/200 mg BID arm compared with the $400 / 100 \mathrm{mg}$ twice daily arm, suggesting that the ritonavir dose affects lopinavir drug levels. In Group 2, there was a significantly higher incidence of gastrointestinal side effects for the $400 / 200$ twice daily arm, compared with the $400 / 100$ twice daily arm [29].

Table 4. Abbot 720 Trial of Lopinavir/Ritonavir [29]

\begin{tabular}{|c|c|c|c|}
\hline LPV/r Dose (BID) & $\mathbf{2 0 0 / 1 0 0 m g}$ & $\mathbf{4 0 0 / 1 0 0 m g}$ & $\mathbf{4 0 0 / 2 0 0}$ \\
\hline \hline N & 16 & 51 & 33 \\
\hline Baseline CD4 & 471 & 335 & 275 \\
\hline Baseline HIV RNA & 4.9 & 4.9 & 5.0 \\
\hline Race (\% Caucasian) & $75 \%$ & $73 \%$ & $66 \%$ \\
\hline Gender (\% male) & $85 \%$ & $94 \%$ & $64 \%$ \\
\hline $\mathbf{4 8}$ Week Efficacy Data (ITT) & & & \\
\hline Percent HIV RNA $<400$ & $100 \%$ & $88 \%$ & $73 \%$ \\
\hline Percent HIV RNA $<50$ & $100 \%$ & $75 \%$ & $73 \%$ \\
\hline 48 week CD4 rise (mean) & +210 & +250 & +200 \\
\hline
\end{tabular}

Despite the strong efficacy of the $200 / 100 \mathrm{mg}$ twice daily dose seen in PI naïve patients, the the 400/100 twice daily dose was chosen for Phase 3 development. The aim may have been to target both PI naïve and PI pre-treated patients with a single uniform dose. However this leaves the possibility of using a lower lopinavir/ $r$ dose for PI naïve patients (including those failing first-line NNRTI based HAART in developing countries). The study population in this Phase 2 trial had a high baseline body weight and was composed predominantly of male Caucasians. People in developing countries are more likely to have low body weight, so drug levels of lopinavir (and therefore antiretroviral efficacy) are likely to be higher for people taking lopinavir/ $\mathrm{r}$ in developing countries. Given the correlation between lopinavir dose and GI toxicity in the Phase 2 trial, lower doses of lopinavir/r may also be better tolerated in people with lower body weight.

Later in development, a clinical trial compared a 400/100 mg twice daily versus $800 / 200$ once daily doses of lopinavir/r in 190 treatment naïve patients [30]. The mean 
Cmin for the $800 / 200$ once daily dose was $3.22 \mathrm{ug} / \mathrm{L}$, which is similar to the Cmin for the $200 / 100 \mathrm{mg}$ twice daily dose in the table above. The $800 / 200 \mathrm{mg}$ once daily dose led to noninferior efficacy compared to the 400/100 BID dose, and HIV RNA reductions were not correlated with lopinavir drug levels in this PI naïve population.

In a cohort study, 28 patients in France with HIV RNA levels below 50 copies/ml on lopinavir/r 400/100 mg twice daily had their dose reduced to $266 / 66 \mathrm{mg}$ twice daily, using the old soft gelatin capsule formulation [31]. HIV RNA levels remained suppressed below 50 copies $/ \mathrm{ml}$ for 48 weeks in 25 of the 28 patients, with two patients showing HIV RNA levels between $50-400$ copies $/ \mathrm{ml}$ and one true virological failure. Without a control group it is difficult to know the true efficacy of the lower dose, but these results do rule out a substantial loss of efficacy lopinavir/ $r$ dose reductions. In addition, the HIVNAT 019 trial evaluated two doses of lopinavir/ritonavir - 400/100 mg BID and 266/66 mg twice daily - in combination with saquinavir in 48 treatment naïve patients. This study also showed no differences in efficacy between the doses [32].

A meta-analysis of clinical pharmacology studies of lopinavir/ritonavir [33] suggests that the dose of 200/50 twice daily (one Meltrex tablet twice daily) would give lopinavir drug levels $50 \%$ lower than the standard dose. The pharmacokinetics of lopinavir are highly dependent on the dose of ritonavir used, and higher doses of ritonavir can compensate for lower doses of lopinavir. So an alternative is to use a 200/150 twice daily dose (one Meltrex tablet and one ritonavir tablet twice daily), which would then provide predicted lopinavir drug levels close to that of the approved dose. Summary results from the meta-analysis are shown in Fig. (1). A prospective clinical pharmacology trial is in progress, to validate the findings from the meta-analysis. If a 200/150mg twice daily dose of lopinavir/ritonavir could be established as efficacious, the cost of lopinavir/ritonavir could be lowered from $\$ 500$ to $\$ 350$ per person-year. The main efficacy trials of lopinavir/ritonavir were conducted using the soft-gelatin formulation, but the use of the new Meltrex formulation has led to lopinavir plasma AUC plasma levels $25-36 \%$ higher than the original soft-gel formulation in the Abbott 730 trial [27]. Use of the Meltrex formulation for the $200 / 150 \mathrm{mg}$ twice daily dose could raise the lopinavir drug levels, compensating for the slightly lower predicted levels at this dose. The higher dose of ritonavir in the $200 / 150 \mathrm{mg}$ twice daily dosage of lopinavir/ritonavir might increase the risk of gastrointestinal side effects. However the increase in ritonavir is only $50 \mathrm{mg}$ twice daily compared to the currently approved dose of 400/100 mg BID; randomized trials are needed to show the clinical consequences of this change in dose. If the $200 / 50 \mathrm{mg}$ twice daily dose could be established as efficacious, the cost of lopinavir/ritonavir could be lowered to $\$ 250$ per person-year.

\section{CONCLUSIONS AND IMPLICATIONS}

1. The evidence from the dose-ranging trials of raltegravir, efavirenz and lopinavir/ritonavir suggest that there is the potential to re-define the doses of these three key antiretrovirals. Lower doses could improve the safety profiles of these drugs, lower costs and make co-formulations more feasible.

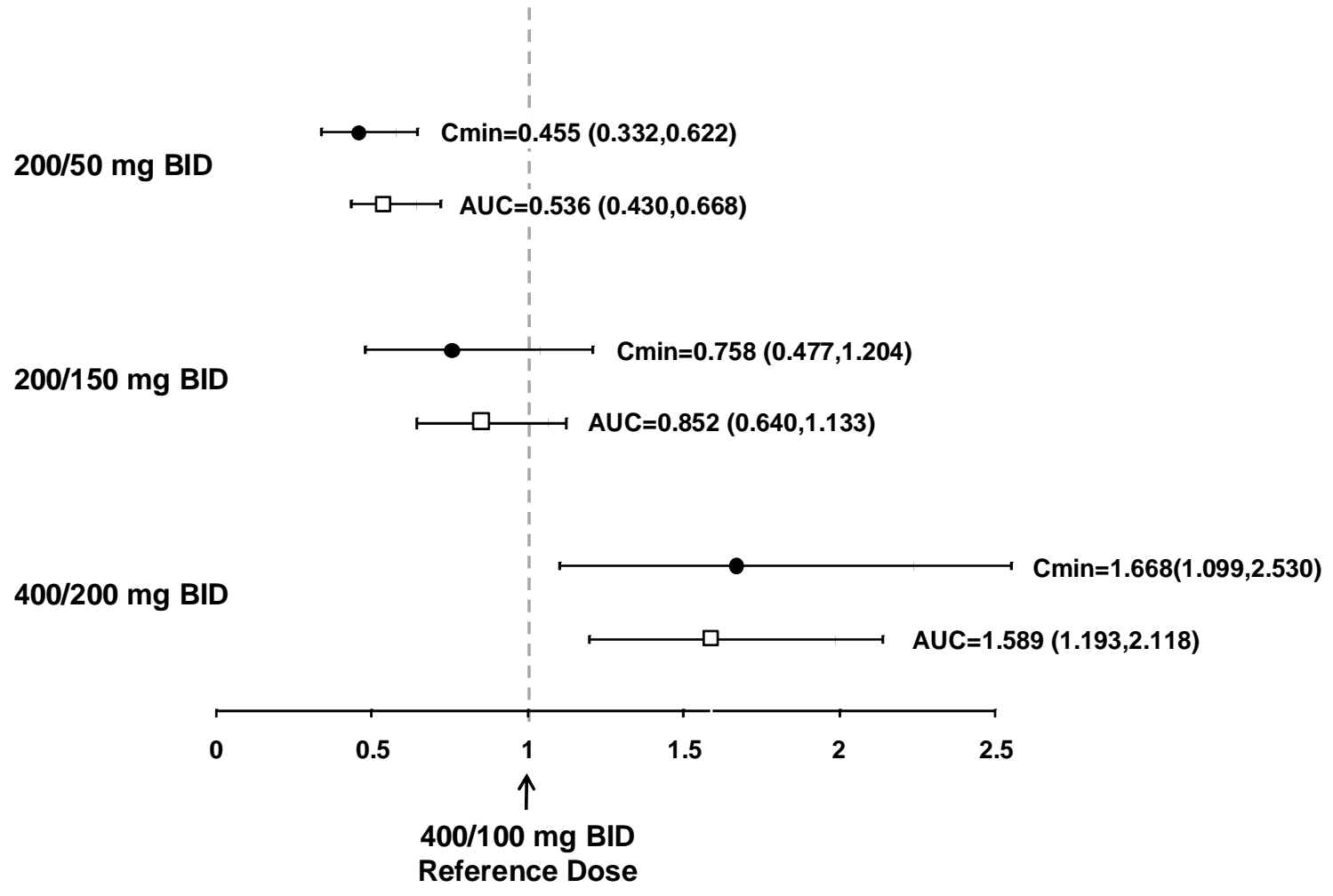

Each line shows the Geometric Mean Ratio and associated 95\% confidence intervals for each new dose of lopinavir/ritonavir, relative to the standard dose of 400/100 mg BID.

Fig. (1). Predicted pharmacokinetics of lopinavir/ritonavir at alternative doses. 
2. Large pivotal dose-ranging trials are needed to establish efficacy of lower doses of antiretrovirals [34]. The designs of these trials have been well defined and have been used to switch from twice daily to once daily dosing of lamivudine, abacavir and lopinavir/ritonavir [34]. Briefly, non-inferiority trial designs are used, with 600-700 patients randomised to receive either the new or the standard dose of the antiretroviral, combined with standard background antiretroviral treatment for the population being evaluated. A Data Safety Monitoring Board would then monitor ongoing results, and decide on the continuation of the trial at interim analyses.

3. There are potential risks as well as benefits from evaluating lower doses of antiretrovirals. There might be a higher risk of treatment emergent drug resistance, under-exposure leading to virological failure, or less ability to withstand drug-drug interactions which lower exposures. However these are theoretical concerns, which have not been bourne out of the dose-ranging programmes so far. Even so, large wellcontrolled trials are required to carefully evaluate new doses of antiretrovirals before they can be approved for widespread use.

4. If these new doses show equivalent efficacy to the standard doses in well-controlled non-inferiority trials, they should be adopted for use in developed as well as developing countries. There could be safety and economic benefits to any country switching to the re-optimised doses.

\section{REFERENCES}

[1] UNAIDS, WHO, UNICEF: TOWARDS UNIVERSAL ACCESS: Scaling up priority HIV/AIDS interventions in the health sector. Update 2009. Available on-line at: http: //www.who.int/hiv/pub/tu apr_2009_en.pdf [Accessed 2009].

[2] Mugenyi P. Flat-line funding for PEPFAR: a recipe for chaos. Lancet 2009; 374: 292.

[3] Medecins Sans Frontieres. Untangling the Web of Antiretroviral Price Reductions: A pricing guide for the purchase of ARVs for developing countries. Upcoming $12^{\text {th }}$ ed. Pre-publication price analysis-2009. Available online at: http://www.msfaccess.org/file admin/user_upload/diseases/hiv-aids/Untangling_the_Web/Untangl ingtheWeb12_prepublicationpriceanalysis_July09pdf.pdf [Accessed October 2009].

[4] President's Emergency Programme for AIDS Relief (PEPFAR). Summary Table of number treated for HIV. Available online at: http: //www.pepfar.gov/about/tables/treatment/123461.htm [Accessed 2009].

[5] Clinton HIV-AIDS Initiative. Antiretroviral price list 2009. Available on-line at: http: //www.clintonfoundation.org/files/chai arvpricelistaugust2009english.pdf [Accessed 2009].

[6] Pinheiro E, Vasan A, Kim J, Lee E, Guimier J, Perriens J. Examining the production costs of antiretroviral drugs. AIDS 2006; 20(13): 1745-52.

[7] Volberding P, Lagakos S, Koch $\mathrm{S}$ et al. Zidovudine in asymptomatic HIV infection. A controlled trial in persons with fewer than 500 CD4-positive cells per cubic millimetre. N Engl J Med 1990; 322: 941-9.

[8] Kahn J, Lagakos S, Richman D, et al. A controlled trial comparing continued zidovudine with didanosine in human immunodeficiency virus infection. N Engl J Med 1992; 327: 581-7.

[9] Hill A, Ruxrungtham K, Hanvanich M, et al. Systematic review of clinical trials evaluating low doses of stavudine as part of antiretroviral treatment. Expert Opin Pharmacother 2007; 8 (5): 110.
[10] World Health Organisation. Addendum to 2006 HIV Treatment Guidelines. Available at: http: //www.who.int/hiv/art/ARTadultsad dendum.pdf [Accessed 2009].

[11] Pozniak A, Morales-Ramirez J, Mohap L, et al. 48-Week Primary Analysis of Trial TMC278-C204: TMC278 Demonstrates Potent and Sustained Efficacy in ART-naïve Patients. $14^{\text {th }}$ International Conference on Retroviruses and Opportunistic Infections, Los Angeles, USA, 2007. Oral abstract 144LB. http://www. retroconference.org/2007/Abstracts/30659.htm

[12] Lennox J, DeJesus E, Lazzarin A, et al. Safety and efficacy of raltegravir-based versus efavirenz-based combination therapy in treatment-naïve patients with HIV-1 infection: a multicentre, double-blind randomized controlled trial. Lancet 2009; 374: 796806.

[13] Cooper D, Gatell J, Rockstroh J, et al. 48-Week results from BENCHMRK-1, a Phase III study of raltegravir in patients failing antiretroviral therapy with triple class resistant HIV-1. 15 ${ }^{\text {th }}$ Conference on Retroviruses and Opportunistic Infections (CROI), Boston, USA 2008 [abstr. 788].

[14] Ellis D. Global trends in the HIV marketplace. $11^{\text {th }}$ International symposium on HIV infection, Bangkok, Thailand 2008.

[15] Markowitz M, Morales-Ramirez J, Nguyen B, et al. Antiretroviral activity, pharmacokinetics and tolerability of MK-0518, a novel inhibitor of HIV-1 integrase, dosed as monotherapy for 10 days in treatment naïve HIV-1 infected individuals. J Acquir Immun Defic Syndr 2006; 43: 509-15.

[16] Markowitz M, Nguyen B, Gotuzzo E, et al. Rapid and durable antiretroviral effect of the HIV-1 integrase inhibitor raltegravir as part of combination therapy in treatment-naïve patients with HIV-1 infection. J Aquir Immun Defic Syndr 2007; 46: 125-33.

[17] Grinsztejn B, Nguyen B, Katlama C, et al. Safety and efficacy of the HIV-1 integrase inhibitor raltegravir (MK-0518) in treatment experienced patients with multidrug-resistant virus: a Phase II randomized controlled trial. Lancet 2007; 369: 1261-9.

[18] Neely M, Decosterd L, Fayet A, et al. Pharmacokinetics of once daily raltegravir and atazanavir in healthy volunteers. $5^{\text {th }}$ IAS Conference on HIV Pathogenesis, Cape Town, South Africa 2009 [abstr 2124].

[19] Iwamoto M, Wenning L, Petry A, et al. Safety, tolerability and pharmacokinetics of raltegravir after single and multiple doses in healthy subjects. Clin Pharm Ther 2008; 83: 293-9.

[20] Hammer S, Eron J, Reiss P, et al. Antiretroviral treatment of Adult HIV infection. 2008 recommendations of the International AIDS Society-USA panel. JAMA 2008; 300(5): 555-70.

[21] Haas D, Hicks C, Seekins D et al. A Phase II, double blind, placebo controlled, dose-ranging study to assess the antiretroviral activity and safety of efavirenz (DMP-266) in combination with open-label zidovudine with lamivudine at 24 weeks (DMP 266-005). $5^{\text {th }}$ Conference on Retroviruses and Opportunistic Infections, Chicago, 1998 [abstract 698).

[22] ENCORE Trial. Available on www.clinicaltrials.gov. Accessed 2010. Available from: http://www.clinicaltrials.gov/ct2/show/ NCT01011413?term $=$ efavirenz\&rank $=31$

[23] Haas D, Ribaudo H, Kim R, et al. Pharmacogenetics of efavirenz and central nervous system side effects: an Adult AIDS Clinical Trials Group study. AIDS 2004; 18: 2391-400.

[24] Burger D, van der Helden I, la Porte C, et al. Interpatient variability in the pharmacokinetics of the HIV non-nucleoside reverse transciptase inhibitor efavirenz: the effect of gender, race and CYP2D6 polymorphism. Br J Pharmacol 2006: 61(2), 148-54.

[25] Marzolini C, Telenti A, Decosterd LA, et al. Efavirenz plasma levels can predict treatment failure and central nervous system side effects in HIV-1 infected patients. AIDS 2001; 15: 71-5.

[26] Klein C, Chiu Y, Awni W, Zhu T, Heuser R, Doan T. The tablet formulation of lopinavir/ritonavir provides similar bioavailability to the soft-gelatin capsule formulation with less pharmacokinetic variability and diminished food effect. J Acquir Immune Defic Syndr 2007; 44: 401-10.

[27] Klein C, Xiong J, Ng J, et al. Comparison of lopinavir and ritonavir tablet and soft gelatin capsule pharmacokinetics in antiretroviralnaïve HIV-1 infected subjects. $9^{\text {th }}$ International Workshop on Clinical Pharmacology of HIV Therapy, New Orleans, USA 2008 [abstr P37].

[28] Flexner C, Chiu Y-L, Foit C, et al. Steady-state pharmacokinetics and short-term virologic response to two lopinavir-ritonavir (LPV/r) high-dose regimens in multiple antiretroviral experienced 
subjects (Study 049). Second IAS Conference on HIV Pathogenesis and Treatment, Paris France 2003 [Abstr 843].

[29] Murphy R, Brun S, Hicks C, et al. ABT-378/ritonavir plus stavudine and lamivudine for the treatment of antiretroviral-naïve adults with HIV-1 infection: 48 week results. AIDS 2001; 15: 1-9.

[30] Johnson M, Gathe J, Podzdamczer D, et al. A Once-daily lopinavirritonavir based regimen provides non-inferior antiviral activity compared with a twice daily regimen. J Acquir Immun Defic Syndr 2006; 43, 153-60.

[31] Meynard J, Lacombe K, Poirier J, et al. Virological Efficacy and Impact on Lipids Profile of a Reduced Dosing ( 2 tablets BID ) of Lopinavir/Ritonavir (LPV/r) in HIV Infected Patients. (Kaledose
Trial). 46th ICAAC September 2006, San Francisco, USA 2006 [abstr H-1384].

[32] Van der Lugt J, Autar RS, Ubolyam S, et al. Pharmacokinetics and short-term efficacy of a double-boosted protease inhibitor regimen in treatment-naive HIV-1-infected adults. J Antimicrob Chemother 2008; 61(5): 1145-53.

[33] Hill A, Van der Lugt J, Boffito M. How much ritonavir is needed to boost protease inhibitors? Systematic review of 17 dose-ranging pharmacokinetic trials. AIDS 2009 [e-published ahead of print].

[34] Hill A, Sabin C. Designing and interpreting HIV noninferiority trials in naïve and experienced patients. AIDS 2008; 22: 913-21.

(C) Hill et al.; Licensee Bentham Open.

This is an open access article licensed under the terms of the Creative Commons Attribution Non-Commercial License (http://creativecommons.org/licenses/ by-nc/3.0/) which permits unrestricted, non-commercial use, distribution and reproduction in any medium, provided the work is properly cited. 